\title{
Relationship of epigenetic variability of miR-124 to extracellular matrix remodelling and age-related MMP-3 expression in rheumatoid arthritis
}

\author{
Monika Pávková Goldbergová1, Jolana Lipková1, Jan Fedorko ${ }^{1}$, Petr Němec², Jindřiška Gatterová3, \\ Lucie Válková ${ }^{1}$ Jana Ševčíková ${ }^{1}$ and Anna Vašků ${ }^{1}$ \\ ${ }^{1}$ Institute of Pathological Physiology, Faculty of Medicine, Masaryk University, Brno, Czech Republic \\ ${ }^{2}$ Rheumatology Division, St. Anne's University Hospital Brno, Faculty of Medicine, Masaryk University, Brno, Czech Republic \\ ${ }^{3}$ Institute of Rheumatology, Prague, Czech Republic
}

\begin{abstract}
The aim of study was to examine relation among miR-124 and serum levels of selected cytokines and chemokines, MMP-3, production of auto-antibodies, and factors describing clinical activity (DAS28) and radiographic progression in rheumatoid arthritis (RA). A total of 80 RA patients according to the ACR classification criteria, and 32 control subjects were recruited into study. The measurements of miR-124 and U-6 expression, CRP, anti-CCP, rheumatoid factors (RFs), radiographs of both hands with calculation of total sharp score (TSS), DAS28 and cytokines, chemokines and MMP levels in serum were obtained from all RA patients. miR-124 was down-regulated in RA patients compared to controls (7-fold decrease). The miR-124 expression correlated to MMP-3 levels $(p<0.001)$, which were in multivariate analysis associated to age of RA onset. Higher levels were detected in younger subjects. No relation of miR-124 expression to measures of RA activity (DAS28 score; TSS), auto-antibodies (anti-CCP, RF, RF IgG, RF IgA, RF IgM), acute inflammatory markers (CRP, IL-6), and other cytokine and chemokines (IL-13, IL-15, IL-8, TNF- $\alpha$, MCP-1, RANTES) was observed. In conclusion, we present a down-regulation of miR-124 in RA patients and its correlation to MMP-3 levels, which associated to age of RA onset.
\end{abstract}

Key words: Rheumatoid arthritis — Protein — microRNA — Expression - MMP

\section{Introduction}

Rheumatoid arthritis (RA) is one of the most common autoimmune, chronic and inflammatory disease affecting $\sim 1 \%$ of the population worldwide (Gramling and O'Dell 2012; RuyssenWitrand et al. 2012). Although the molecular mechanism of RA pathogenesis is not fully understood, the important role of microRNAs in immune response is widely discussed (Persengiev 2012). The microRNAs (miRNAs) belong to non-coding group of single-stranded RNAs, with the size of approximately 19-23 nucleotides. Even though miRNAs are not translated into the protein, they play important role in the regulation of the gene expression, and thus in regulation

Correspondence to: Monika Pávková Goldbergová, Institute of Pathological Physiology, Faculty of Medicine, Masaryk University, Kamenice 5, 62500 Brno, Czech Republic

E-mail: goldberg@med.muni.cz of many biological processes, such as maturation, differentiation, proliferation, migration, metastasis, apoptosis and stress responses (Bartel 2004; Esquela-Kerscher and Slack 2006; Gangaraju and Lin 2009; Qin et al. 2016). The expression of more than $60 \%$ of protein-coding genes is regulated by nowadays known 5000-10000 mammalian miRNAs (Sun et al. 2013), which are moreover complementary to one or more mRNAs.

Generally, primary miRNA is cleaved in nucleus to the hairpin structure called pre-miRNA, which is then transported to cytoplasm (Lee et al. 2003), where is the premiRNA processed into mature functional miRNA (Hammond 2005). Binding of the miRNA to the target mRNA induces its degradation or translation repression by three main mechanisms: inhibition of translation, inhibition of the initiation of translation and destabilization of target mRNA (Hutvagner 2005; Chu and Rana 2007; Stefani and Slack 2008) (Figure 1). Aberrant miRNA expression is related to initiation and progression of pathophysiological processes 


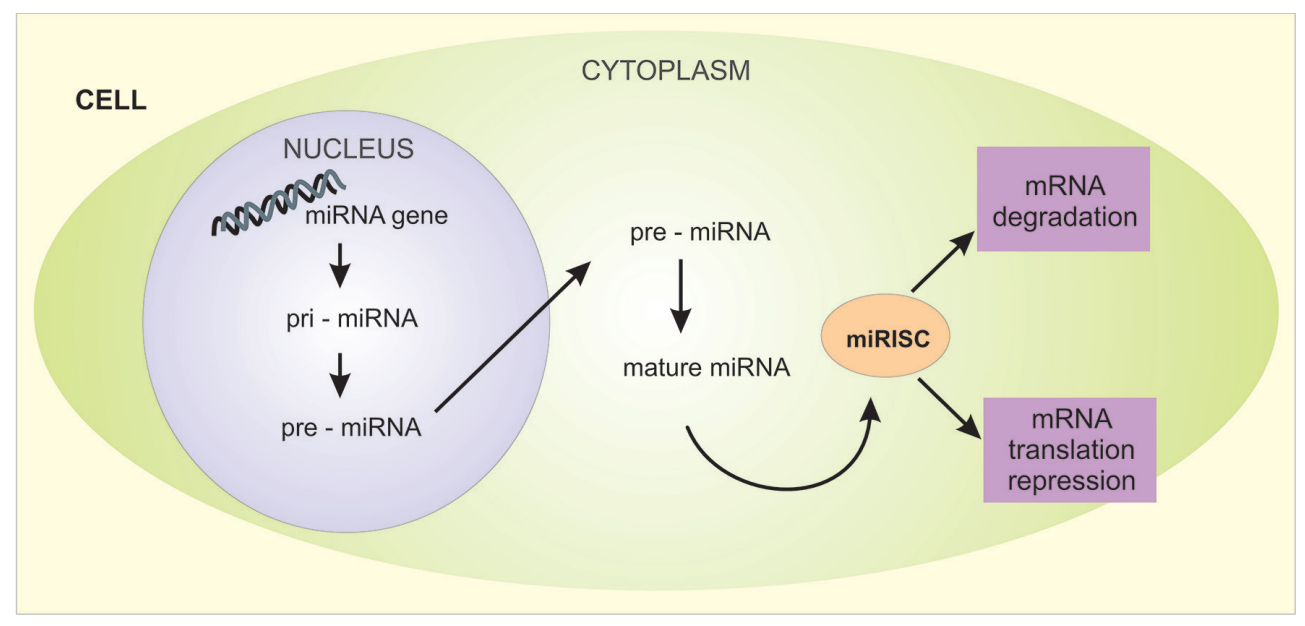

Figure 1. Maturation and effect of miRNAs. Primary miRNA is cleaved in nucleus by Drosha enzyme to the hairpin structure called pre-miRNA, which is then transported to cytoplasm (Lee et al. 2003). There the pre-miRNA is processed into mature functional miRNA by cleavage mediated by Dicer endoribonuclease, forming a miRNA duplex (Hammond 2005). One of the miRNA strands binds to the miRISC, guides the complex to the $3^{\prime}$ - untranslated region ( $3^{\prime}$ UTR) of the target mRNA and induce its degradation or translation repression by three main mechanisms: inhibition of translation, inhibition of the initiation of translation and destabilization of target mRNA (Hutvagner 2005; Chu and Rana 2007; Stefani and Slack 2008).

such as carcinogenesis, asthma, psoriasis, systemic lupus erythematosus and also rheumatoid arthritis, where altered expression regulate cell proliferation and inflammation of synovial fibroblasts (Nakamachi et al. 2009; Kawano and Nakamachi 2011; Pekow and Kwon 2012).

miR-124 (5'-UAAGGCACGCGGUGAAUGCC-3' (SEQ ID NO:1)) have three subtypes, miR-124-1, miR-124-2 and miR-124-3, which have distinct chromosome locations and encode the same mature miR-124. miR-124 is expressed in neuronal cells, in the immune cells, peripheral

Table 1. Demographic, clinical, and laboratory characteristics of rheumatoid arthritis (RA) patients

\begin{tabular}{lcc}
\hline \multirow{2}{*}{ Characteristics } & \multicolumn{2}{c}{ Values } \\
\cline { 2 - 3 } & RA $(n=80)$ & Controls $(n=54)$ \\
\hline Age (year) & $56.9(20.2-82.1)$ & $54.3(25.3-72.7)$ \\
Sex (women) & ${ }^{a} 61(76.3)$ & ${ }^{a} 42(77.8)$ \\
Disease duration (year) & $11.0(2.0-50.2)$ & 0 \\
Swollen joints & $6(0-24)$ & 0 \\
Tender joints & $5(0-26)$ & 0 \\
DAS 28 & $3.88(1.03-7.58)$ & $0 a$ \\
TSS/year & $1.11(0-11.59)$ & 0 \\
RF positivity & $65(81.3)$ & 0 \\
IgM RF positivity & $\mathrm{a}_{52}(65.0)$ & ${ }^{2} 2(3.7)$ \\
IgA RF positivity & $\mathrm{a}_{28} 2(35.0)$ & 0 \\
IgG RF positivity & ${ }^{\mathrm{a}} 53(66.3)$ & ${ }^{\mathrm{a}} 1(1.9)$ \\
anti-CCP positivity & ${ }^{\mathrm{a}} 89(61.8)$ & 0 \\
\hline
\end{tabular}

Values are given as median (5\% and $95 \%$ precentil) or as ${ }^{a}$ number (percentage). DAS28, disease activity score 28 ; TSS/year, the annual radiographic progression rate of the Total Sharp Score; RF, rheumatoid factor; anti-CCP, anticyclic citrullinated peptide. blood mononuclear cells, bone marrow, lymph node and thymus (Lagos-Quintana et al. 2002). miR-124 is a critical modulator of development of immune system, and plays role in regulation of immune system. miR-124 is thus involved in autoimmune disorders by targeting various molecules related to activation of the RhoA/ROCK pathway (An et al. 2013), matrix metalloproteinases (MMPs) (Xu et al. 2013), epithelial-mesenchymal transitive (Qin et al. 2014) and epigenetic modification ( $\mathrm{Li}$ et al. 2013).

Our study investigates the relationship among the variation in miRNA-124 expression and onset and/or progression of RA including the factors describing rheumatoid arthritis. The study further focuses on evaluation of biomarkers such levels of selected cytokines and chemokines, and markers of extracellular matrix (ECM) remodeling in the relation to the selected miRNA expression.

\section{Methods}

\section{Patient population}

A total of 80 patients with RA diagnosed according to the revised classification criteria of the American College of Rheumatology were consecutively recruited into the study over a 3-year period (Table 1). Patients with RA were recruited from the outpatient populations of the Rheumatology Division, 2nd Department of Internal Medicine, St. Anne's University Hospital, Brno. All subjects were Caucasians from Moravian regions of the Czech Republic.

The study was approved by the Committee for Ethics of Medical Experiments on Human Subjects, Faculty of Medicine, Masaryk University, Brno. Informed consent was 
obtained from all individual participants included in the study. The study was in agreement with the Declaration of Helsinki approved at the World Medical Association meeting in Edinburgh.

Blood samples were obtained from all patients at the time of clinical examination for determination of erythrocyte sedimentation rate (ESR), C-reactive protein (CRP), presence of rheumatoid factors (RFs), and anti-cyclic citrullinated peptide autoantibody (anti-CCP). Serum levels of IgM RF, IgA RF, and IgG RF isotypes were determined using an ELISA assay (Aeskulisa Rf - A, G, N; Aesku Diagnostics, Wendelsheim, Germany). Serum levels of anti-CCP were measured by ELISA assay (ELISA KIT anti-CCP, Genesis Diagnostics, Cambridgeshire, UK).

\section{Radiographic analysis}

All patients enrolled in the study underwent radiographs of the hands. X-ray findings of hands were scored by one observer using the modified Sharp/van der Heijde method. The total sharp score (TSS) and the annual radiographic progression rate from the disease onset (TSS/year) were calculated. Median of TSS/year was 1.11. All RA patients were classified into two groups according to the annual radiographic progression rate: those with TSS/year $\leq 1.11$ and those with TSS/year $>1.11$.

\section{Laboratory methods}

\section{Serum collection and storage}

In brief, blood samples were obtained from all patients in the cardiac catheterization laboratory. Centrifugation was carried out for $15 \mathrm{~min}$ at $1000 \times \mathrm{g}$. Supernatant was aspirated, centrifuged, and stored at $-80^{\circ} \mathrm{C}$ until assayed.

\section{Biochemical tests}

Standard biochemical and hematological blood tests were performed immediately upon hospital admission including selected cytokines and chemokines (IL-6, IL-13, IL-15 (Pavkova Goldbergova et al. 2014), IL-8, TNF- $a$ (Pavkova Goldbergova et al. 2012a), MCP-1, RANTES (Pavkova Goldbergova et al. 2012b), and proteolytic enzyme MMP (MMP-3) with use of ELISA kits (GE Life Science, UK).

\section{miRNA}

Total RNA extraction from serum was performed using the TRIzol reagent (Invitrogen, Carlsbad, CA). Reverse transcription into cDNA was performed using the TaqMan microRNA reverse transcription kit with specific harpin primers (Applied Biosystems, Foster City, CA). The expres- sion of miRNA-124 was performed by real-time RT-PCR using an ABI 7700 system (Applied Biosystems). miRNAU6 was used as an endogenous control. For each individual sample, the expression value was calculated based on reference miRNA (U6) according to a threshold cycle (Ct) value for each serum sample. To avoid the difficulties in detection of low expression values $(>40 \mathrm{Ct})$, the preamplification was applied. The results are shown using relative quantification $(\Delta \mathrm{Ct})$ and $(\Delta \Delta \mathrm{Ct})$.

\section{Statistics}

Values are expressed as median with $25^{\text {th }}$ and $75^{\text {th }}$ percentile. The Kruskal-Wallis ANOVA and Mann Whitney U tests were used for the evaluation of miRNA expression levels and other continual variants. Correlation analyses were performed using two-tailed Spearman's rank correlation. Multivariate linear regression was applied for adjustment the influence of other variables. Parameters with $p<0.10$ were taken into multivariate analysis, and if applicable were square root transformed. Statistica v. 10.0 (Statsoft Inc., Tulsa, OK) was used to analyze the data. The values with $p<0.05$ were considered significant. Bonferroni correction was applied to adjust the alpha level according to the number of independent comparisons to an overall value of 0.05 .

\section{Results}

The expression of miRNA-124a in circulation was analyzed in 80 RA subjects and 54 controls. miR-124 was downregulated in RA patients compared to controls $(p<0.01 ; \Delta \mathrm{Ct}$ median RA $4.4 v s .0 .36$ ), with the decrease of in RA subjects ( $\Delta \Delta \mathrm{Ct}$ 0.139) (Figure 2). Regarding the clinical parameters of RA, no relation was observed among miR-124 expression and parameters of clinical disease activity: DAS28 score $(p=$ $0.51)$, radiographic progression: TSS $(p=0.89)$, and autoantibodies: anti-CCP $(p=0.14), \operatorname{RF}(p=0.29), \operatorname{RF} \operatorname{IgG}(p=$ $0.63), \operatorname{RF} \operatorname{IgA}(p=0.92), \operatorname{RF} \operatorname{IgM}(p=0.70)$.

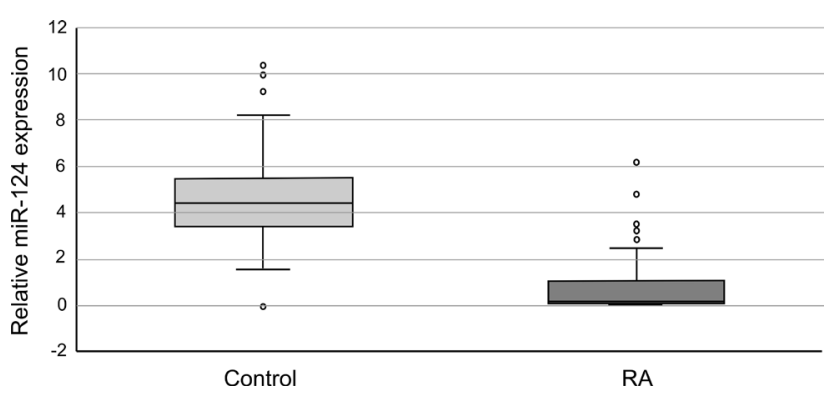

Figure 2. Expression of miRNA-124 in circulation between groups of patients with rheumatoid arthritis (RA) and controls. 
Table 2. Correlations among miR-124 expression and serum levels of selected cytokines, cheomkines, MMP, and measures of disease activity $^{*}$

\begin{tabular}{lccc}
\hline miR-124 & $n$ & $\mathrm{~S}_{\mathrm{r}}$ & $p$ \\
\hline IL-6 & 73 & 0.013 & 0.91 \\
TNF- $\alpha$ & 73 & 0.066 & 0.58 \\
IL-8 & 73 & -0.033 & 0.78 \\
IL-13 & 73 & -0.059 & 0.62 \\
IL-15 & 73 & -0.069 & 0.57 \\
TSS & 73 & -0.015 & 0.89 \\
X-ray St. & 73 & 0.134 & 0.25 \\
DAS28 & 73 & -0.079 & 0.51 \\
HAQ & 73 & 0.171 & 0.18 \\
CRP & 73 & 0.138 & 0.25 \\
FW & 73 & 0.007 & 0.95 \\
RF & 45 & 0.159 & 0.29 \\
RF IgG & 73 & 0.057 & 0.63 \\
RF IgA & 73 & -0.011 & 0.92 \\
RF IgM & 73 & 0.045 & 0.70 \\
Anti-CCP & 73 & -0.178 & 0.14 \\
MCP-1 & 40 & 0.225 & 0.15 \\
RANTES & 40 & 0.131 & 0.52 \\
MMP-3 level & 50 & -0.572 & $<\mathbf{0 . 0 0 1}$ \\
\hline
\end{tabular}

${ }^{\star}$ Spearman rank order coefficients $\left(S_{\mathrm{r}}\right)$ are shown in the corresponding cells; results with $p<0.05$ with Bonferroni correction are in bold and underlined. IL, interleukin; TNF, tumour necrosis factor; CRP, C-reactive protein; HAQ, health assessment questionnaire; DAS28, 28-joint disease activity score; X-ray st., $\mathrm{X}$-ray stage; TSS, radiographic progression rate of the total sharp score; FW, erythrocyte sedimentation; RF, rheumatoid factor; Ig, immunoglobulin; anti-CCP, anticyclic citrullinated peptide; MCP-1, monocyte chemotactic protein 1; RANTES, regulated on activation, normal T-cell expressed and secreted; MMP, matrix metalloproteinase.

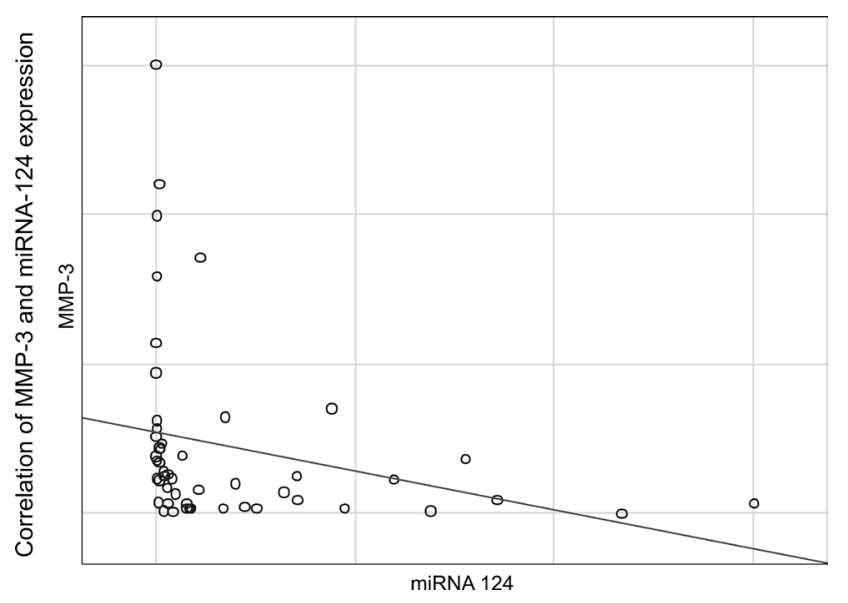

Figure 3. Correlation of miRNA-124 expression with the level of matrix metalloproteinase-3 (MMP-3).
Relationships among the miR-124 and selected inflammatory and remodelling markers in RA patients are presented in Table 2. The subjects with at least one missing variable were excluded from the analyses. According to the Spearman's coefficient $\left(\mathrm{S}_{\mathrm{r}}\right)$, the major correlation of miR-124 expression was found with the level of extracellular matrix remodelling marker MMP-3 $\left(\mathrm{S}_{\mathrm{r}}=-0.572 ; p<0.001\right)$ (Table 2; Figure 3). No relationship was confirmed among miR-124 expression and acute inflammatory markers (CRP, $p=0.25$; IL-6, $v=$ 0.91 ), other cytokines and chemokines (IL-13, $p=0.62$; IL$15, p=0.57$; IL-8, $p=0.78$; TNF- $\alpha, p=0.58$; MCP- $1, p=0.37$; RANTES, $p=0.47$ ) (Table 2). According to the Spearman's coefficient, some relation exist among MMP-3 serum level and levels of IL-6 $\left(\mathrm{S}_{\mathrm{r}}=-0.291 ; p=0.02\right)$, and CRP $\left(\mathrm{S}_{\mathrm{r}}=\right.$

Table 3. Correlations among MMP-3 level in circulation and serum levels of selected cytokines, and measures of disease activity*

\begin{tabular}{llcc}
\hline MMP-3 & $n$ & $\mathrm{~S}_{\mathrm{r}}$ & $p$ \\
\hline IL-6 & 62 & -0.291 & $\mathbf{0 . 0 2}$ \\
CRP & 62 & -0.247 & $\mathbf{0 . 0 5}$ \\
HAQ & 53 & -0.257 & 0.06 \\
TSS & 62 & -0.050 & 0.69 \\
X-ray st. & 62 & -0.178 & 0.15 \\
DAS28 & 62 & 0.004 & 0.97 \\
RF & 62 & -0.182 & 0.26 \\
RF IgG & 62 & 0.045 & 0.72 \\
RF IgA & 62 & -0.048 & 0.71 \\
RF IgM & 62 & 0.052 & 0.69 \\
Anti-CCP & 62 & -0.165 & 0.20 \\
TNF- $\alpha$ & 62 & -0.146 & 0.26 \\
IL-15 & 62 & -0.040 & 0.76 \\
\hline
\end{tabular}

${ }^{\star}$ Spearman rank order coefficients $\left(\mathrm{S}_{\mathrm{r}}\right)$ are shown in the corresponding cells; results with $p<0.05$ are in bold. IL, interleukin; TNF, tumour necrosis factor; CRP, C-reactive protein; HAQ, health assessment questionnaire; DAS28, 28-joint disease activity score; $\mathrm{X}$-ray st., X-ray stage; TSS, radiographic progression rate of the total sharp score; RF, rheumatoid factor; Ig, immunoglobulin; anti-CCP, anticyclic citrullinated peptide; MMP, matrix metalloproteinase.

Table 4. Multivariate linear analysis of factors with independent relationship to MMP-3 level

\begin{tabular}{lccc}
\hline MMP-3 & Coefficient $(95 \%$ CI $)$ & Beta $(ß)$ & $p$ \\
\hline age at entry & $-0.014(-0.024 ;-0.003)$ & -0.322 & $\mathbf{0 . 0 1}$ \\
IL-6 at entry & $-0.018(-0.039 ; 0.001)$ & -0.238 & 0.06 \\
CRP at entry & $0.013(-0.012 ; 0.037)$ & 0.137 & 0.29 \\
gender & $-0.001(-0.001 ; 0.001)$ & -0.037 & 0.77 \\
\hline
\end{tabular}

Results with $p<0.05$ are in bold. MMP, matrix metalloprotease; IL, interleukin; CRP, C reactive protein. Only variables were taken into multivariate analysis, in which a significant relationship was found in univariate linear regression. 
$-0.247 ; p=0.05$ ), respectively (Table 3 ). The independent factor according to multivariant linear model in the relationship with the MMP-3 levels in circulation is age of the RA onset and in a trend the level of IL-6 (Table 4). When the MMP-3 levels (median $102.15 \mathrm{ng} / \mathrm{ml}, 25^{\text {th }}$ and $75^{\text {th }}$ percentile 26.89-380.16 ng/ml) were divided according to median age ( 57.1 years), higher levels were detected in the younger age at the entry (median, $25^{\text {th }}$ and $75^{\text {th }}$ percentile: $152.71 \mathrm{ng} / \mathrm{ml}$, 60.99-291.50 ng/ml vs. $64.63 \mathrm{ng} / \mathrm{ml}, 18.36-155.62 \mathrm{ng} / \mathrm{ml}$ ).

\section{Discussion}

Currently, increasing attention is paid to the miRNAs as potential biomarkers of various diseases including autoimmune disorders. In our study, the miR-124 was down-regulated in RA patients compared to control subjects. Our results are in consensus with recent studies describing the miR-124 down-regulation in synovial tissues of RA patients compared with that in patients with osteoarthritis (OA) (Nakamachi et al. 2009; Miao et al. 2013). The main characteristic features of RA are persistent inflammation, synovial hyperplasia, lymphocyte infiltration and abnormal proliferation of fibroblast-like synoviocytes (FLS), which eventually lead to progressive cartilage erosion and bone destruction (Cooles and Isaacs 2011). Nakamachi et al. 2009 found that miR-124 level in RA FLS was less than one-sixth of that in OA FLS (Nakamachi et al. 2009). Suggested reason is the epigenetic dysregulation, the higher miR-124 promoter methylation, in RA patients that leads to decreased levels of this miRNA and thus could be involved in the onset and/or progression of RA (Zhou et al. 2013).

The production of cytokines and chemokines by fibroblast-like synoviocytes and macrophage-like synoviocytes leads to many pathologic and clinical manifestation of RA (Firestein 2003). The miR-124 has many potential targets, according to TargetScanHuman from 20121654 transcripts with conserved sites. Among first identified targets of miR124 is monocyte chemotactic protein-1 (MCP-1) (Nakamachi et al. 2009), which is involved in inflammation, tissue infiltration as one of the major chemotactic proteins in RA, proved in work by Pavkova Goldbergova et al. (2012b). Other known targets of miR-124 that could be discussed in RA concerning inflammation are cyklin dependent kinase (CDK-2; cell cycle) (Stanczyk et al. 2011), nuclear factor of activated T-cells (NFAT) (Kang et al. 2013; Wang et al. 2015), regulatory factor X (RFX-1; affecting HLA class II expression) (Feng et al. 2016), Stress-associated endoplasmic reticulum protein 1 (SERP-1) (Mucaj et al. 2015). Ponomarev et al. (2011) also found that over-expression of miR-124 inhibits expression of TNF- $a$. Even such huge number of targets of miR-124, we have not associated its expression to acute inflammatory markers (CRP, IL-6), and/or other cytokine and chemokines (IL-13, IL-15, IL-8, TNF- $\alpha$, MCP-1, RANTES). Also no relation of miR-124 expression to measures of RA activity and progression (structural or radiographic) and auto-antibodies (anti-CCP, RF, RF IgG, RF IgA, RF IgM) was observed. But as mentioned above, the miR-124 expression affects the extracellular matrix remodelling. In our study we have correlated its expression to matrix metalloproteinase 3 (MMP-3; stromelysin-1) levels, and furthermore the MMP-3 levels were related to IL-6 and CRP levels in circulation.

MMPs are the key molecules involved in the joint destruction in RA, and are mainly produced among others by synovial lining cells, neutrophils and macrophages (Okada et al. 1992). MMP-3 has the broadest substrate specificity of the MMP family and can degrade proteoglycans, laminin, fibronectin, and collagens III, IV, IX and X (Okada et al. 1986). Serum levels of MMP-3 are correlated with markers of inflammation and are suggested as one of the strongest independent predictor of radiographic disease progression (Houseman et al. 2012), which was proved also on the DNA level (Nemec et al. 2007). Thus plays an important role in the ethiopathogenesis of rheumatoid arthritis from the onset and also thru the progression of the disease, while MMP3 is produced by fibroblasts in response to increased levels of pro-inflammatory cytokines and causes joint degradation (Birkedal-Hansen 1993; Stachowska et al. 2009). Even though the direct effect of miR-124 on MMP-3 levels is not known according to our best knowledge, MMP-3 is not a direct target of the miR-124. Even though we expect the indirect effect of pro-inflammatory miRNAs on the targets involved in the extracellular matrix development and remodelling; the direct targets are: Laminin gamma1 (LAMC1; ECM protein) and integrin beta1 (ITGB1; cellmatrix adhesion molecule) (Cao et al. 2007), bone morphogenic protein 6 (BMP-6), and collagen type IV 1 alpha (COL4A1).

Regarding the association of MMP-3 level with the age at the entry, it is widely accepted that MMP-3 levels increase with the range of joint destruction. Furthermore, the levels were highly correlated with the articular parameters such as the swollen and painful joint counts (Ichikawa et al. 1998). Concerning our results, the serum MMP-3 levels were reported to be an indicator for the development of radiological damage in patients with early RA (Cheung et al. 2000; Yamanaka et al. 2000). But on the other hand, Ainola et al. (2005) reported that MMP-3 serum levels do not necessarily correlate with the local tissue destructive events in case of tight binding of MMP-3 to its substrate. Furthermore, the level of MMP-3 in circulation could be also modified by glucocorticoids and NSAIDs, the most commonly used drugs for RA treatment. Sadowski and Steinmeyer (2001) reported inhibition of MMP-3 expression by meloxicam and indomethacin on bovine chondrocytes. The reduction of MMP-3 production by indomethacin was also proved on 
human chondrocytes (Yamada et al. 1996). Moreover, it was referred that the biological therapy with soluble TNF- $a$ receptor (etanercept) significantly down-regulates serum levels of MMP-3 (Catrina et al. 2002). But in our study in such selected group, the levels of MMP-3 in patients treated by the biological therapy $(142.86 \mathrm{ng} / \mathrm{ml})$ were not significantly different from the rest of RA patients.

Our study has limitations. First of all, these are results from an observational study, and the analyses were limited by a small number of patients. Second, the limitation is the absence of the MMP-3 levels in circulation before the therapy, which could affect its production. Also the expression of miRNAs in circulation could be affected by contamination of the source from the various blood cell types as mentioned in recent reports (McDonald et al. 2011; Blondal et al. 2013), so the cell content should be minimalised by standard procedure (e.g. EDRN Standard Oerating Procedures). The serum samples were underwent double-centrifugations, which could minimalise the contamination.

In conclusion, miRNA-124 is marker of RA, which on the other hand cannot be correlated to disease activity, progression and/or prognosis of patient outcome. Nonetheless, an interesting finding was the correlation of miRNA-124 expression with circulating matrix metalloproteinase 3 levels, the marker of extracellular matrix remodelling. Further, the MMP-3 levels were in multivariate analysis associated to age of RA onset, with higher levels detected in younger subjects. Although our findings would need further confirmation in larger studies, a better understanding of the role of microRNA-dependent regulation of the processes of disease development may lead to new targeted therapies and new diagnostics for rheumatoid arthritis.

Acknowledgment. This study was funded by Masaryk University grant (MUNI/A/1297/2017).

Conflict of interest. The authors declare that they have no conflict of interest.

\section{References}

Ainola MM, Mandelin JA, Liljeström MP, Li TF, Hukkanen MVJ, Konttinen YT (2005): Pannus invasion and cartilage degradation in rheumatoid arthritis: involvement of MMP-3 and interleukin-1beta. Clin. Exp. Rheumatol. 23, 644-650

An L, Liu Y, Wu A, Guan Y (2013): microRNA-124 inhibits migration and invasion by down-regulating ROCK1 in glioma. PLoS ONE 8, e69478

https://doi.org/10.1371/journal.pone.0069478

Bartel DP (2004): MicroRNAs: genomics, biogenesis, mechanism, and function. Cell 116, 281-297 https://doi.org/10.1016/S0092-8674(04)00045-5

Birkedal-Hansen H (1993): Role of matrix metalloproteinases in human periodontal diseases. J. Periodontol. 64, 474-484
Blondal T, Nielsen SJ, Baker A, Andreasen D, Mouritzen P, Teilum MW, Dahlsveen IK (2013): Assessing sample and miRNA profile quality in serum and plasma or other biofluids. Methods 59, S1-S6 https://doi.org/10.1016/j.ymeth.2012.09.015

Cao X, Pfaff SL, Gage FH (2007): A functional study of miR-124 in the developing neural tube. Genes Dev. 21, 531-536 https://doi.org/10.1101/gad.1519207

Catrina AI, Lampa J, Ernestam S, Af Klint E, Bratt J, Klareskog L, Ulfgren A-K (2002): Anti-tumour necrosis factor (TNF)-alpha therapy (etanercept) down-regulates serum matrix metalloproteinase (MMP)-3 and MMP-1 in rheumatoid arthritis. Rheumatology (Oxford) 41, 484-489 https://doi.org/10.1093/rheumatology/41.5.484

Cheung NT, Dawes PT, Poulton KV, Ollier WE, Taylor DJ, Mattey DL (2000): High serum levels of pro-matrix metalloproteinase- 3 are associated with greater radiographic damage and the presence of the shared epitope in patients with rheumatoid arthritis. J. Rheumatol. 27, 882-887

Chu C-Y, Rana TM (2007): Small RNAs: regulators and guardians of the genome. J. Cell. Physiol. 213, 412-419 https://doi.org/10.1002/jcp.21230

Cooles FAH, Isaacs JD (2011): Pathophysiology of rheumatoid arthritis. Curr. Opin. Rheumatol. 23, 233-240 https://doi.org/10.1097/BOR.0b013e32834518a3

Esquela-Kerscher A, Slack FJ (2006): Oncomirs - microRNAs with a role in cancer. Nat. Rev. Cancer 6, 259-269 https://doi.org/10.1038/nrc1840

Feng C-Z, Yin J-B, Yang J-J, Cao L (2016): Regulatory factor X1 depresses ApoE-dependent A $\beta$ uptake by miRNA-124 in microglial response to oxidative stress. Neuroscience 344, $217-228$ https://doi.org/10.1016/j.neuroscience.2016.12.017

Firestein GS (2003): Evolving concepts of rheumatoid arthritis. Nature 423, 356-361 https://doi.org/10.1038/nature01661

Gangaraju VK, Lin H (2009): MicroRNAs: key regulators of stem cells. Nat. Rev. Mol. Cell Biol. 10, 116-125 https://doi.org/10.1038/nrm2621

Gramling A, O'Dell JR (2012): Initial management of rheumatoid arthritis. Rheum. Dis. Clin. North Am. 38, 311-325 https://doi.org/10.1016/j.rdc.2012.05.003

Hammond SM (2005): Dicing and slicing: the core machinery of the RNA interference pathway. FEBS Lett. 579, 5822-5829 https://doi.org/10.1016/j.febslet.2005.08.079

Houseman M, Potter C, Marshall N, Lakey R, Cawston T, Griffiths I, Young-Min S, Isaacs JD (2012): Baseline serum MMP-3 levels in patients with Rheumatoid Arthritis are still independently predictive of radiographic progression in a longitudinal observational cohort at 8 years follow up. Arthritis Res. Ther. 14, R30 https://doi.org/10.1186/ar3734

Hutvagner G (2005): Small RNA asymmetry in RNAi: function in RISC assembly and gene regulation. FEBS Lett. 579, 5850-5857 https://doi.org/10.1016/j.febslet.2005.08.071

Ichikawa Y, Yamada C, Horiki T, Hoshina Y, Uchiyama M (1998): Serum matrix metalloproteinase- 3 and fibrin degradation 
product levels correlate with clinical disease activity in rheumatoid arthritis. Clin. Exp. Rheumatol. 16, 533-540

Kang K, Peng X, Zhang X, Wang Y, Zhang L, Gao L, Weng T, Zhang H, Ramchandran R, Raj JU, Gou D, Liu L (2013): MicroRNA-124 suppresses the transactivation of nuclear factor of activated $\mathrm{T}$ cells by targeting multiple genes and inhibits the proliferation of pulmonary artery smooth muscle cells. J. Biol. Chem. 288, 25414-25427 https://doi.org/10.1074/jbc.M113.460287

Kawano S, Nakamachi Y (2011): miR-124a as a key regulator of proliferation and MCP-1 secretion in synoviocytes from patients with rheumatoid arthritis. Ann. Rheum. Dis. 70 (Suppl. 1), i88-91 https://doi.org/10.1136/ard.2010.138669

Lagos-Quintana M, Rauhut R, Yalcin A, Meyer J, Lendeckel W, Tuschl T (2002): Identification of tissue-specific microRNAs from mouse. Curr. Biol. 12, 735-739 https://doi.org/10.1016/S0960-9822(02)00809-6

Lee Y, Ahn C, Han J, Choi H, Kim J, Yim J, Lee J, Provost P, Rådmark O, Kim S, Kim VN (2003): The nuclear RNase III Drosha initiates microRNA processing. Nature 425, 415-419 https://doi.org/10.1038/nature01957

Li L, Luo J, Wang B, Wang D, Xie X, Yuan L, Guo J, Xi S, Gao J, Lin X, et al. (2013): Microrna-124 targets flotillin-1 to regulate proliferation and migration in breast cancer. Mol. Cancer 12, 163 https://doi.org/10.1186/1476-4598-12-163

McDonald JS, Milosevic D, Reddi HV, Grebe SK, Algeciras-Schimnich A (2011): Analysis of circulating microRNA: preanalytical and analytical challenges. Clin. Chem. 57, 833-840 https://doi.org/10.1373/clinchem.2010.157198

Miao C, Yang Y, He X, Xu T, Huang C, Huang Y, Zhang L, Lv X-W, Jin Y, Li J (2013): New advances of microRNAs in the pathogenesis of rheumatoid arthritis, with a focus on the crosstalk between DNA methylation and the microRNA machinery. Cell. Signal. 25, 1118-1125 https://doi.org/10.1016/j.cellsig.2013.01.024

Mucaj V, Lee SS, Skuli N, Giannoukos DN, Qiu B, EisingerMathason TS, Nakazawa MS, Shay JE, Gopal PP, Venneti S, et al. (2015): MicroRNA-124 expression counteracts pro-survival stress responses in glioblastoma. Oncogene 34, 2204-2214 https://doi.org/10.1038/onc.2014.168

Nakamachi Y, Kawano S, Takenokuchi M, Nishimura K, Sakai Y, Chin T, Saura R, Kurosaka M, Kumagai S (2009): MicroRNA124 a is a key regulator of proliferation and monocyte chemoattractant protein 1 secretion in fibroblast-like synoviocytes from patients with rheumatoid arthritis. Arthritis Rheum. 60, 1294-1304 https://doi.org/10.1002/art.24475

Nemec P, Pavkova-Goldbergova M, Gatterova J, Vasku A, Soucek $\mathrm{M}$ (2007): Association of the $5 \mathrm{~A} / 6 \mathrm{~A}$ promoter polymorphism of the MMP-3 gene with the radiographic progression of rheumatoid arthritis. Ann. N. Y. Acad. Sci. 1110, 166-176 https://doi.org/10.1196/annals.1423.019

Okada Y, Nagase H, Harris ED (1986): A metalloproteinase from human rheumatoid synovial fibroblasts that digests connective tissue matrix components. Purification and characterization. J. Biol. Chem. 261, 14245-14255
Okada Y, Shinmei M, Tanaka O, Naka K, Kimura A, Nakanishi I, Bayliss MT, Iwata K, Nagase H (1992): Localization of matrix metalloproteinase 3 (stromelysin) in osteoarthritic cartilage and synovium. Lab. Invest. 66, 680-690

Pavkova Goldbergova M, Pavek N, Lipkova J, Jarkovsky J, Stouracova M, Gatterova J, Vasku A, Soucek M, Nemec P (2012a). Circulating cytokine pattern and factors describing rheumatoid arthritis: IL-15 as one of the biomarkers for RA? Biomarkers 17, 655-662 https://doi.org/10.3109/1354750X.2012.719036

Pavkova Goldbergova M, Lipkova J, Pavek N, Gatterova J, Vasku A, Soucek M, Nemec P (2012b): RANTES, MCP-1 chemokines and factors describing rheumatoid arthritis. Mol. Immunol. 52, 273-278 https://doi.org/10.1016/j.molimm.2012.06.006

Pavkova Goldbergova M, Nemec P, Lipkova J, Jarkovsky J, Gatterova J, Ambrozkova D, Vasku A, Soucek M, Pavek N (2014): Relation of IL-6, IL-13 and IL-15 gene polymorphisms to the rheumatoid factors, anti-CCP and other measures of rheumatoid arthritis activity. Int. J. Immunogenet. 41, 34-40 https://doi.org/10.1111/iji.12065

Pekow JR, Kwon JH (2012): MicroRNAs in inflammatory bowel disease. Inflamm. Bowel Dis. 18, 187-193 https://doi.org/10.1002/ibd.21691

Persengiev SP (2012): miRNAs at the crossroad between hematopoietic malignancies and autoimmune pathogenesis. Discov. Med. 13, 211-221

Ponomarev ED, Veremeyko T, Barteneva N, Krichevsky AM, Weiner HL (2011): MicroRNA-124 promotes microglia quiescence and suppresses EAE by deactivating macrophages via the C/EBP- $\alpha$-PU.1 pathway. Nat. Med. 17, 64-70 https://doi.org/10.1038/nm.2266

Qin W, Pan Y, Zheng X, Li D, Bu J, Xu C, Tang J, Cui R, Lin P, Yu X (2014): MicroRNA-124 regulates TGF- $\alpha$-induced epithelialmesenchymal transition in human prostate cancer cells. Int. J. Oncol. 45, 1225-1231 https://doi.org/10.3892/ijo.2014.2506

Qin Z, Wang P-Y, Su D-F, Liu X (2016): miRNA-124 in Immune System and Immune Disorders. Front. Immunol. 7, 406 https://doi.org/10.3389/fimmu.2016.00406

Ruyssen-Witrand A, Constantin A, Cambon-Thomsen A, Thomsen $M$ (2012): New insights into the genetics of immune responses in rheumatoid arthritis. Tissue Antigens 80, 105-118 https://doi.org/10.1111/j.1399-0039.2012.01939.x

Sadowski T, Steinmeyer J (2001): Effects of non-steroidal antiinflammatory drugs and dexamethasone on the activity and expression of matrix metalloproteinase-1, matrix metalloproteinase- 3 and tissue inhibitor of metalloproteinases- 1 by bovine articular chondrocytes. Osteoarthr. Cartil. 9, 407-415 https://doi.org/10.1053/joca.2000.0406

Stachowska E, Dolegowska B, Dziedziejko V, Rybicka M, Kaczmarczyk M, Bober J, Rac M, Machalinski B, Chlubek D (2009): Prostaglandin E2 (PGE2) and thromboxane A2 (TXA2) synthesis is regulated by conjugated linoleic acids (CLA) in human macrophages. Acta Physiol. Pol. 60, 77

Stanczyk J, Ospelt C, Karouzakis E, Filer A, Raza K, Kolling C, Gay R, Buckley CD, Tak PP, Gay S, Kyburz D (2011): Altered expression of microRNA-203 in rheumatoid arthritis synovial 
fibroblasts and its role in fibroblast activation. Arthritis Rheum. 63, 373-381 https://doi.org/10.1002/art.30115

Stefani G, Slack FJ (2008): Small non-coding RNAs in animal development. Nat. Rev. Mol. Cell Biol. 9, 219-230 https://doi.org/10.1038/nrm2347

Sun Y, Li Q, Gui H, Xu D-P, Yang Y-L, Su D-F, Liu X (2013): MicroRNA-124 mediates the cholinergic anti-inflammatory action through inhibiting the production of pro-inflammatory cytokines. Cell Res. 23, 1270-1283 https://doi.org/10.1038/cr.2013.116

Wang Y, Huang C, Chintagari NR, Xi D, Weng T, Liu L (2015): miR-124 regulates fetal pulmonary epithelial cell maturation. Am. J. Physiol. Lung Cell Mol. Physiol. 309, L400-413 https://doi.org/10.1152/ajplung.00356.2014

Xu X, Li S, Lin Y, Chen H, Hu Z, Mao Y, Xu X, Wu J, Zhu Y, Zheng X, Luo J, Xie L (2013): MicroRNA-124-3p inhibits cell migration and invasion in bladder cancer cells by targeting ROCK1. J. Transl. Med. 11, 276

https://doi.org/10.1186/1479-5876-11-276
Yamada H, Kikuchi T, Nemoto O, Obata K, Sato H, Seiki M, Shinmei M (1996): Effects of indomethacin on the production of matrix metalloproteinase- 3 and tissue inhibitor of metalloproteinases- 1 by human articular chondrocytes. J. Rheumatol. 23, 1739-1743

Yamanaka H, Matsuda Y, Tanaka M, Sendo W, Nakajima H, Taniguchi A, Kamatani N (2000): Serum matrix metalloproteinase 3 as a predictor of the degree of joint destruction during the six months after measurement, in patients with early rheumatoid arthritis. Arthritis Rheum. 43, 852-858

https://doi.org/10.1002/1529-0131(200004)43:4<852::AID-ANR16>3.0.CO;2-7

Zhou Q, Long L, Shi G, Zhang J, Wu T, Zhou B (2013): Research of the Methylation Status of miR-124a Gene Promoter among Rheumatoid Arthritis Patients. J. Immunol. Res. 2013, e524204

Received: January 28, 2018

Final version accepted: July 5, 2018

First published online: November 15, 2018 